\title{
'Passivity': A Model of Grocery Retail Price Decision-Making Practice
}

\section{Iain Watson}

Edinburgh Business School, Heriot-Watt University, Edinburgh, Scotland

Steve Wood

Surrey Business School, University of Surrey, Guildford, England

John Fernie

School of Management, University of St Andrews, St Andrews, Scotland

Corresponding author: Steve Wood

Corresponding author email: sm.wood@surrey.ac.uk

\section{Author biographies}

Iain Watson holds a doctorate in retail pricing and is a leading independent business and IT consultant to UK and US retailers in the areas of planning; merchandising, including pricing; and supply chain. He can be contacted at Iain.Watson@IpsumPlus.com

Steve Wood is Professor of Retail Marketing \& Management at Surrey Business School, University of Surrey. He has held previous positions at University of Southampton, in the marketing department of Tesco plc and in retail analysis at Verdict Research. He can be contacted at sm.wood@ @urrey.ac.uk

John Fernie is Honorary Professor of Retail Marketing at School of Management, University of St Andrews and an Emeritus Professor at Heriot-Watt University. He has written and contributed to numerous textbooks and papers on retail management, especially in the field of retail logistics and the internationalisation of retail formats. Between 1989 and 2009, he was editor of the International Journal of Retail and Distribution Management. He can be contacted at jf91@st-andrews.ac.uk

THIS IS A MICROSOFT WORD VERSION OF THE ACCEPTED PAPER CURRENTLY FORTHCOMING IN EUROPEAN JOURNAL OF MARKETING (DECEMBER 2014)

IF CITING PLEASE REFER TO THE PUBLISHED VERSION IN THE JOURNAL. MANY THANKS. 


\title{
'Passivity': A Model of Grocery Retail Price Decision-Making Practice
}

\begin{abstract}
Purpose - This paper explores the applied context of grocery retail pricing practice to understand how pricing executives approach 'regular price' decision-making (as opposed to promotional pricing). The study seeks to inductively develop a model of regular price decision-making in grocery retailing.

Methodology - The research employs an inductive methodology involving interviews with pricing executives working for grocery retailers that account for approximately $85 \%$ of UK, and $64 \%$ of US, grocery market retail sales. Our approach is appropriate given the underdeveloped research insights into regular pricing within food retailers.

Findings - We find that regular pricing is undertaken with little sophistication; typically on the basis of simple, inflexible rules that result in conflicting goals. We identify a typology of three pricing roles, though all share an underdeveloped understanding of the effects of price changes on customer demand and the implications of competitor reactions. These contexts, causes and conditions lead to a range of consequences; notably a degree of pricing inertia, 'customer-less' pricing, and 'enforced symbiosis' - coping outcomes. Taken together we identify a theory of "passivity" pricing.

Originality/value - The research presents a contribution to new knowledge in the field of retail marketing by developing theory in retail pricing. In contrast to much extant research on grocery pricing, this paper accesses the insights and opinions of the pricing executives themselves. It exposes the realities of regular price decision-making across two developed retail markets and offers managerial insights.
\end{abstract}

Keywords: retailing, pricing, grocery retailing, EDLP, HiLo, food retailing

Article classification: Research paper

Revised submission to European Journal of Marketing. December 2014

\section{Introduction}

Grocery retailing within the UK and US is fiercely competitive and characterised by thin margins. For example, US grocery retailers' net profits average only approximately $1.5 \%-190^{\text {th }}$ out of 215 industries in terms of net profit margin performance (Hemscott Americas, 2012). Consequently, small adjustments to price charges can have significant implications for retailer performance. Dolan and Simon's (1996) well-known study suggested a 10\% improvement in pricing resulted in a $33 \%$ improvement in profit; far higher than any other business lever. Conversely, a 7\% reduction in retail price, based on average grocery margins, needs an almost unprecedented $32 \%$ improvement in volume just to break even in profit (Hoch et al. 1994). As a result, 'pricing decisions are regarded as being among the most crucial and difficult aspects in retail marketing' (McGoldrick, 2002, p.247), yet they are also among the most complex given that a typical superstore will offer between 30,000 and 40,000 stock keeping units (SKUs) (Zielke, 2010).

Pricing feeds into the image customers generate of retailers (Jensen and Grunert, 2014; Zielke, 2010, 2011) and, while this may be moderated by customer background and shopping mission, it remains one of the key variables that affects patronage behaviour (Angell et al., 2012; Megicks et al., 2008). Price plays a key role in a retailer's competitive positioning and therefore represents considerable sunk investment cost (Ellickson et al., 2012). However, despite the importance of price to profits, it is suggested that retailers are not particularly strategic in price management - 'most retailers do not use price as a basis for achieving a sustainable competitive advantage' (Levy et al., 2004, p.13) and 'prefer to use cost-plus pricing or market-based pricing versus customer focused value pricing' 
(Phillips, 2005, p.24). Indeed, little research into actual grocery pricing practices exists in the academic literature, with minimal insights from the perspective of executives responsible for pricing.

Our paper has two objectives. First, we discuss and explore the applied context of grocery pricing by practitioners ${ }^{1}$ to understand how they, and their firms, approach regular price decision-making. Second, we inductively develop a model of regular pricing practice that explains the actions of regular price decision makers within the UK and US grocery markets. To achieve these objectives and conscious of the potential inconsistency between strategy and actual practice within the firm (Jarzabkowski and Spee, 2009), we pursue an inductive methodology employing interviews with lead pricing decision-makers within retail firms across the two retail markets. The behavioural model that emerges from our data provides valuable practical insight for retail marketing management, as well as providing much-needed context to academic pricing research. In doing so, it seeks to address the theory-practice divide within retail marketing in respect of retail pricing ( $c f$. Lee and Greenley, 2010; Reibstein et al., 2009) - but more specifically, the long-standing concern that 'the pricing literature has produced few insights...that would stimulate most businessmen to change their methods of setting prices', given the lack of 'realism in their theoretical structure' (Oxenfeldt, 1973, p 48).

The paper is structured as follows: In the following two sections, we briefly explore the retail marketing literature concerning grocery retail pricing strategies (visible in the marketplace) and price setting practices (hidden behind the boundaries of the firm) to assess how grocers are understood to make product pricing decisions ${ }^{2}$. We then explain our methodological approach, before discussing our interview results. The analysis of results allows the development of a model of grocery retail price decision-making behaviour which we then reflect on in a discussion and conclusion section.

\section{Grocery pricing strategies}

Most writers characterize a grocer's pricing strategy as one of either offering stable low prices across the assortment, 'Every Day Low Price' (EDLP), or offering deep and frequent price promotions on a narrow range of goods, normally referred to as 'HiLo' pricing or some 'HYBRID' between the two (see Fassnacht and El Husseini, 2013 for a review; see also Bell and Lattin, 1998; Blattberg and Neslin, 1990; Lal and Rao, 1997). In a recent analysis of the US retail market, EDLP and HYBRID stores were found to perform more strongly than HiLo retailers in generating weekly sales (Gauri, 2013; see also Volpe, 2011) though the execution of pricing strategy should be considered in the context of (and in combination with) any multi-format strategy (Gauri et al., 2008; Haans and Gijsbrechts, 2011). A greater variation in grocery pricing strategy is suggested in Bolton and Shankar's study of US supermarkets' pricing behaviours across 200 grocery stores in 17 chains, over a 2-year time period (Shankar and Bolton, 2004; Bolton and Shankar, 2003). They found that although chains and stores employed EDLP and HiLo as signalling strategies, retailers actually practiced as many as five different pricing strategies at the brand level (see Table 1).

Table 1 Pricing strategies identified in the US grocery market by Bolton and Shankar

\begin{tabular}{|l|l|l|l|l|}
\hline & \multicolumn{4}{|c|}{ Pricing dimensions } \\
\hline $\begin{array}{l}\text { Pricing strategy } \\
\text { (\% prevalent) }\end{array}$ & Relative price & Price variation & Deal intensity & Deal support \\
\hline Exclusive pricing (8\%) & High & Medium & Low & Low \\
\hline Moderately promotional pricing (14\%) & Average & Medium & Medium & Medium \\
\hline HiLo pricing (11\%) & Average & High & High & High \\
\hline EDLP (45\%) & Average & Low & Medium & Medium \\
\hline Aggressive pricing (22\%) & Average & High & Low & Medium \\
\hline
\end{tabular}

Source: Bolton et al., 2010; Bolton and Shankar, 2003

An array of research demonstrates that retailers, while perceived as fitting into neat strategy boxes, often realise very different strategies at the store shelf-edge (Ellickson and Misra, 2008; Gauri et al., 2008; Shankar and Bolton, 2004). Whether this is deliberate or accidental is not entirely clear, due in part to most retailers' sensitivity to revealing their pricing practices. Furthermore, Ellickson and 
Misra (2008) demonstrate that a grocer's price strategy is not always determined and executed at chain level. Bell and Lattin (1998) found evidence that firms react to the local customer base and adapt their corporate strategy at the store level to accommodate local needs. These local needs included competing grocers and the imperative to adopt a similar pricing strategy to 'coordinate their actions' (Ellickson and Misra, 2008, p.822), rather than pursuing a strategy of differentiation. On the one hand, Shankar and Bolton's (2004) study of grocery stores across five US markets suggested competition was a key determinant of prices; in contrast, Nijs et al. (2007), in their study of 55 Denver supermarkets, argued competitor retail prices accounted for only 5.5 per cent of retail price variance.

\section{Grocery pricing practices}

While popular debate considers the possibilities of variable grocery prices (New York Times, 2012) and the potential for 'customized pricing' (Bolton et al., 2010), the published research evidence suggests that UK and US grocery practices suffer from a more fundamental lack of alignment between business strategy and pricing execution (Ellickson and Misra, 2008). The role of local pricing has seemingly diminished as head office based pricing executives introduce a degree of price rigidity and pricing rules. While classical economic theory assumes that 'prices adjust flexibly in response to changes in demand and cost' and therefore retailers select optimal prices based on changes in demand, cost and competitive action, while staying consistent with their pricing strategy (Srinivasan et al. (2008, p.15), Simon et al. (2010, p 287) note that, in reality, the 'textbook paradigm of price optimization is not applicable to retailers, with their typically large ranges, frequent price changes, and price promotions'.

The limited amount of research on actual regular price decision-making suggests there are very different practices pursued in contrast to retail marketing theory. Similarly, Ingenbleek and van der Lans (2013, p.45) refer to 'weak connections between price strategies and price-setting practices'. The wider research within business \& management and organisational psychology explains why this might be so - criticising an assumption of rational decision-making. As March (1997, p.10-11) argues, rational decision-making assumes the decision-maker enjoys knowledge of alternatives for action; understands the consequences of alternative actions sufficient to devise a probability distribution; can consistently order preferences to allow alternative consequences to be compared; and finally, that they 'have rules by which they select a single alternative of action on the basis of its consequences'. In practice, Hodgkinson and Starbuck (2008, p.6) concede that decision-makers 'have neither full information nor the competence and capacities to process the myriad of information that is available, nor do they have perfect knowledge of the issues at hand'.

A decision-maker's rationality is essentially 'bounded' by the information available, the limited cognition of their minds and limited time (Simon, 1959). Consequently, decision-makers resort to employing heuristics which are simple rules of thumb that enable people to cut through complexity (Maule and Hodgkinson, 2002). While this tends to work well in most circumstances, in some cases it can lead to cognitive bias and therefore poor choices (Hodgkinson and Starbuck, 2008, p.8; see Das and Teng, 1999 for a comprehensive summary).

Importantly, it is not only knowledge, limits to cognition, time, and individual biases that affect decision-makers. In addition, organisational context must be considered, with Herbert Simon's view of bounded rationality arguably underplaying the role of political and organisational pressures within businesses. As Miller and Wilson (2006, p.471) argue, such demands 'may be seen more accurately as a game of power in which competing interest groups vie with each other for the control of scarce resources'. These pressures present themselves through bureaucracy, the division of responsibilities and targets as well as the 'interpretive scheme' of the organisation that can lead to embedded forms of analysis, routines, practices and behaviour (Gilbert, 2005; Jarzabkowski and Spee, 2009; Reus et al., 2009). 
Given the limitations of decision-making within organisational contexts, it is perhaps understandable that '[w]hile most companies are savvy about cutting costs, few have figured out how much money they are giving up by using 'lunk-headed' pricing' (Business Week, 2000, cited in Nijs et al., 2007). Diamantopoulos (2003, p.342) contends that many end up relying 'on over-simplistic rules of thumb and place exaggerated emphasis on costs'. Most of our understanding comes from studies that, akin to pricing strategy studies, take in-store prices and try to derive the tactics a decision-maker may have employed (Bolton and Shankar, 2003; Binkley and Connor, 1998; Chintagunta, 2002; Nijs et al., 2007; Shankar and Bolton, 2004; and Srinivasan et al., 2003). Their general findings indicate that grocery retailers commonly set prices relative to historical prices, competitor retail activity, brand demand, wholesale prices, and are partly the product of the internal organisation of the pricing function/supply chain (specifically category management roles and goals).

A reliance on historical pricing appears to have dominated the tactics adopted by retailers, rather than profit maximization through demand-based pricing. Indeed, Bergen et al. (2002) found that past pricing explained over $90 \%$ of the reported price variation in their sample stores. Nijs et al. (2007) concluded that over $50 \%$ of price change variation was explained by reverting prices to those consistent with historical relative prices even though it realised lower margins. Contextual support for this practice of rigidity includes the need to manage complex demand dynamics and multiple objectives, both of which lead pricing managers to revert to the safety of previous prices. Meanwhile, Hall et al. (1997) believed that price rigidity was driven by a desire to retain customer relations and prevent price wars. Nijs et al. (2007) put forward several other rationales including repeating successful sales promotions, despite lower profits (Srinivasan et al. 2003) and resorting to heuristics such as 'satisficing behaviour', making a safe decision rather than an optimal one (Simon, 1959); loss aversion through uncertainty in demand (Kahneman and Tversky, 1979; Rotemberg and Saloner, 1990); and decision anchoring (Nijs et al. 2007).

Despite historical pricing being the overwhelming tactic of choice, research has concluded that prices are often reactive and governed by internal cost or competitors' pricing (Kopalle et al., 2009; Monroe, 2003). Indeed, Kopalle et al.'s (2009, p.57) study suggested that retailers do not have a choice in their reliance on simple pricing practices as 'typical firms do not have the data, energy or analytics to understand complex linkages with respect to pricing, customer reaction, cost and competition'. Instead of customer centric pricing tactics, they stick to 'time-honoured rules' (Levy et al., 2004, p.15) that are easy to calculate and implement in a spreadsheet programme. More generally across retailing, Bolton et al. (2010, p 259) suggest greater sophistication is challenging rules-oriented pricing - with prices increasingly 'generated from statistical modeling and data mining'. In particular, they argue that price optimization software has had the effect of increasing gross margin through reduced markdowns and by better managing the phasing of reductions when necessary. However, the perishable nature of fresh food further complicates this task with academia often providing theoretical rather than practically oriented modelled pricing 'solutions' (Chung and Li, 2014; Wang and Li, 2012). The extent to which such tools have been successfully leveraged to grocery ( $c f$. apparel) pricing practice remains unclear.

Therefore, while there is an extensive literature on long run grocery retail price positioning strategy, we gain fewer insights into the characteristics of the regular price decision-makers; the organisational context within which regular price is set; or how decisions regarding price are made on a daily basis. This is the contribution of this research paper. Indeed, Fassnacht and El Husseini (2013, p 285), in their recent review of retail pricing, note the relative paucity of research from the retailers' perspectives and identify it as a focus of future academic interest:

'[Despite] the fact that pricing strategy is an important concern of the company, many researchers regard this topic from the customer's point of view. It would be desirable if more studies would consider the retailer's perspective, e.g. through interviews ... in the retailing industry'. 


\section{Research methodology}

To address the research aim of developing an explanatory model of grocery regular pricing practice, an inductive interview data collection technique was employed, focused on pricing decision-makers across a sample of UK and US grocery retail firms. Such an exploratory qualitative methodology was deemed most appropriate in guiding the gathering and analysis of data due to the relative scarcity of academic literature and the lack of substantive, or formal, theories that could have been hypothesised and subsequently tested. In the following sections we explain the research design and the process of data analysis which lead to the development of a model of pricing behaviour.

\subsection{Research design}

The research design was determined by: the type of pricing in the study; the retail sector under investigation; the pricing roles included; and the countries involved. We elaborate on these below:

Pricing - Retail product prices can take on multiple guises. This paper deals solely with what is called the 'regular price', also referred to by decision-makers as the 'permanent price'. The regular price is the day-to-day product price excluding any generally available product promotions or temporary price discounts. Regular price decision-making also excludes markdown, clearance pricing decisions, and promotions as these are not normally within the purview of grocery pricing managers.

Retail sector - The research is limited to conventional grocery retailers. Of course, retailers that once only sold grocery products now sell merchandise that compete with other retail sub-verticals (e.g. clothes, general merchandise and pharmacy), and likewise other retail sub-verticals are increasingly selling what was traditionally considered grocery products (Burt et al., 2010). For the sake of research clarity, all of the retailers sampled started their lives as grocers and would most probably be considered by a layperson as grocers. Convenience stores, limited product range grocers, limited assortment discounters, club stores and specialist fresh grocery retailers were considered outside of the sampling frame.

Interview subjects: leading price decision-makers- The process of regular price decision-making is executed by executives with different job titles and varying levels of price specialisation. As the empirical data analysis uncovers, at times these were executives who only dealt with pricing; while at others, also had responsibility for buying within the retail organisation. Our interview subjects are described as 'leading pricing practitioners' as they were the executives within each of the retail organisations who had responsibility for determining the regular shelf price across a group of products and stores. Using this definition kept the research targeted to those who actually made the tactical price change decisions.

Retail markets - To ensure the best chance of theoretically saturating the concepts (Glaser, 1978), the research sample needed to be as large as possible. Persuading any grocery retailer to discuss their price decision-making with a third party, when not under contractual non-disclosure, was always going to be challenging; as demonstrated by the lack of extant academic research. The first author had good relations with a number of large US and UK grocery retailers, and while the initial sample frame contained additional countries, the number of grocers per country risked introducing distracting country specific biases. It was therefore concluded that a sample frame covering the UK and US would be the optimal solution, albeit cognizant of key country differences that potentially impact price decision-making.

Participants - The final project sample consisted of 16 large grocery retailers (six in the UK and 10 in the US) (see Table 2). Executives were contacted initially via email and then by a phone call to agree participation and finalise arrangements. Within each retailer, although the job title varied, we interviewed the executive(s) who had responsibility for the day-to-day management of regular price. In the process, the sample covered retailers that account for approximately $85 \%$ of UK grocery retail sales (Kantar Worldpanel, 2013) and 64\% of the US grocery sales (USDA, 2012). While it was not the intent to carry out a 'stratified purposeful' sample (Wengraf, 2004), the stratification between 
pricing strategies (i.e. EDLP versus HiLo) did allow for a degree of commentary on the differences in pricing practices between decision-makers in the pricing strategy groups.

Table 2 Distribution of interviewees per country, per grocer, and pricing strategy and follow-up sessions and emails per interviewee

\begin{tabular}{|c|c|c|c|c|c|}
\hline Country & Grocer & $\begin{array}{l}\text { Pricing } \\
\text { Strategy }\end{array}$ & $\begin{array}{l}\text { No. of } \\
\text { interviewees }\end{array}$ & $\begin{array}{l}\text { No. of } \\
\text { follow-up } \\
\text { sessions }\end{array}$ & $\begin{array}{l}\text { No. of } \\
\text { follow-up } \\
\text { emails }\end{array}$ \\
\hline UK & $\begin{array}{l}1 \\
2 \\
3 \\
4 \\
5 \\
6\end{array}$ & $\begin{array}{l}\text { HiLo } \\
\text { HiLo } \\
\text { EDLP } \\
\text { HiLo } \\
\text { HiLo } \\
\text { EDLP }\end{array}$ & $\begin{array}{l}1 \\
2 \\
1 \\
1 \\
2 \\
1\end{array}$ & $\begin{array}{l}1 \\
1 \\
1 \\
1\end{array}$ & $\begin{array}{l}1 \\
2\end{array}$ \\
\hline UK Totals & 6 & & 8 & 4 & 3 \\
\hline US & $\begin{array}{l}7 \\
8 \\
9 \\
10 \\
11 \\
12 \\
13 \\
14 \\
15 \\
16\end{array}$ & $\begin{array}{l}\text { HiLo } \\
\text { HiLo } \\
\text { HiLo } \\
\text { EDLP } \\
\text { HiLo } \\
\text { EDLP } \\
\text { EDLP } \\
\text { EDLP } \\
\text { HiLo } \\
\text { HiLo }\end{array}$ & $\begin{array}{l}1 \\
1 \\
1 \\
1 \\
1 \\
1 \\
2 \\
2 \\
1 \\
1\end{array}$ & $\begin{array}{l}1 \\
1 \\
1 \\
1 \\
1 \\
1\end{array}$ & $\begin{array}{l}1 \\
1 \\
2\end{array}$ \\
\hline $\begin{array}{l}\text { US Totals } \\
\text { Grand Totals }\end{array}$ & $\begin{array}{l}10 \\
16\end{array}$ & & $\begin{array}{l}12 \\
20\end{array}$ & $\begin{array}{l}5 \\
9 \\
\end{array}$ & $\begin{array}{l}4 \\
7\end{array}$ \\
\hline
\end{tabular}

\subsection{Data collection and analysis}

The research data were collected through in-depth semi-structured telephone interviews. This was necessary due to its inherent flexibility as a data collection method given the busy and ever-changing schedules of the respondents and the travel costs that would have been prohibitive given the trans-US and UK contexts. We recognise the limitations of such an approach - not least the limited ability to engage in observation and therefore pick up on body language cues that may otherwise have informed the conduct of the discussion (Bryman and Bell, 2011). Telephone interviews may also heighten the risks of overlooking context in the interviews. Specifically for our project, this was a particular risk given that we were only asking respondents about their pricing practices rather than actually measuring or observing them. Indeed, more widely, Alvesson and Sköldberg (2009, p.66) critique our chosen approach of grounded theory for its tendency to decontextualize (in our case, interview) subjects - 'The actors appear to be not people of flesh and blood, but some kind of shadowy Platonic beings'. It is argued that a lack of understanding of context can be particularly damaging for the usefulness of the insights generated, with researchers interpreting what they think they are seeing, in light of their own unreflected frames of reference' (ibid., p.67). Alvesson goes on, suggesting that the highly structured detailed coding operations in grounded theory data analysis are (misguidedly) promoted as a means of overcoming weakness in understanding the context:

'...when all our energy is put into producing, codifying, analysing and reporting such material, it is easy to miss or marginalize a careful appreciation of the uncertainty of the material for the (false) comfort of a naïve empiricism.' (Alvesson, 2011, p.34).

At this juncture, we should acknowledge the positionality of the lead researcher in this project as it is relevant in partly overcoming some of the limitations regarding understanding and context. The lead author is a management consultant to UK and US retailers and undertook the research as part of a part-time doctorate. He often knew many of the interviewees (at least by reputation) having worked with many of them. This is important to the understanding of interview context as it provided the 
interviewer with the knowledge to challenge and probe interviewees concerning points, using a language that was embedded in the parlance of the industry - reminiscent of some of the characteristics of what Alvesson (2003) labels a 'localist' approach. Such a-priori experience of price management by the interviewer, we argue, informed the reflexive nature of data analysis and interpretation of interview events. It allowed an understanding of localised context, while also exhibiting sufficient pragmatism for the information to be practically useful for theory building ( $c f$. Alvesson, 2011, p.29-40).

The 'directed conversations' (Charmaz, 2013) with pricing decision-makers ensured some consistency of questioning, while allowing for a degree of latitude to explore potentially interesting areas. The research instrument was informed by the typology of Kvale and Brinkmann (2008) and consisted of questions closely aligned with the aim of the research. The structure of the interviews followed Wengraf's (2004) pyramid model that ensured a clear line of sight from the overall aim, through theory questions (which were likely formulated in a language unsuitable for interviewees) to ultimate interview questions (which were easily communicated). The instrument progressed through interview topics of retailer and respondent's context (e.g. personal history, retailer pricing strategy, organisational context) and then onto their practices, which included a focus on procedures and protocols, drivers of price changes, approvals required, the data sources employed etc. The questions asked were informed by the literature review concerning overall retailer pricing strategy, the limited research that had been conducted concerning regular pricing practices and, naturally, the lead author's industry experience. The semi-structured nature of the interviews ensured flexibility in the order that questions were asked and the interviewer employed various tactics to ensure that the interviewees provided a sufficient level of detail, such as follow-up and rephrasing questions that had been only partly addressed. The interviews ranged in length from 50 to 85 minutes with additional follow-ups by telephone or via email exchange. Importantly, email was used only to address specific questions that had little potential for ambiguity and could be answered effectively in a written format. The follow-up interviews ranged between ten and 30 minutes in length.

Data was analysed in what has been described as an iterative loop of 'data collecting, coding and analysis' (Glaser and Holton, 2004, p.11). This offered the advantage of immediately immersing the researchers in the study data (Glaser, 1998, p.115). Interview field notes were taken and subjected to initial 'open coding' and initial 'memoing' before moving on to the next interviewee. This is very different from qualitative research that looks to collect all the data prior to embarking on coding and analysis (Wengraf, 2004, p 2). Coding was undertaken by the lead author and followed the approach to data analysis of Barney Glaser who does not advocate the need for inter-rater reliability (Pidgeon and Henwood, 2009), a process which remains the subject of considerable methodological debate (Armstrong et al., 2007). The stages of analysis undertaken are described in detail at the end of the paper $^{3}$.

The following sections analyse the results from the interviews held with UK and US grocery pricing decision-makers, which subsequently informs the development of a model of regular pricing practice. The results section is suffused with the voice of the executives to allow the reader 'to see the data-totheory connections in the form of linkages among the quotes in the text' (Gioia et al., 2013, p.23). Individual quotations are therefore selected on the basis that they particularly illuminate the linkage between the data and constructs in the model that emerge from the data and which is detailed later in the paper.

\section{Pricing roles and the experience of respondents}

The job titles of 'Buyer' and 'Price Manager' appeared consistently across the interviews, accompanied by a group of 'Price Executives', Vice President's (VP's) of Pricing, or Marketing. Regardless of title, all interviewees in the sample operationally led day-to-day regular pricing decisions. 
Table 3 Interviewees by pricing role and country

\begin{tabular}{|l|l|l|l|}
\hline & Country & \multirow{2}{*}{ Totals } \\
\hline Pricing role & UK & US & $\mathbf{6}$ \\
\hline Buyer & 5 & 1 & $\mathbf{6}$ \\
\hline Pricing Executive & & 6 & $\mathbf{8}$ \\
\hline Price Manager & 3 & 5 & $\mathbf{2 0}$ \\
\hline Totals & $\mathbf{8}$ & $\mathbf{1 2}$ & \\
\hline
\end{tabular}

Table 3 shows that in the UK, buyers tended to make operational pricing decisions, whereas in the US these decisions originated from specialist pricing executives. In the UK, the role of pricing manager exists but tends to focus on the creation, day-to-day management, and enforcement of pricing rules for buyers to follow. Buyers were often educated to degree level and then progressed through the company management training scheme. Pricing specialists, executives and managers, commonly had a more varied background, often over a longer retail tenure. Interestingly, these pricing decisionmakers appeared to take their role due to practical circumstance rather than design: 'fell into it by accident' (US 1); 'I don't know, wrong place and the right time' (UK 1); with US 9, a pricing executive, picked for her 'finance background and long history with the company' (US 9). Logically it was the case that often pricing executives had many years' worth of pricing experience, with several having MBA qualifications and significant tenures with their retail firm outside of pricing.

It was somewhat surprising that none of the interviewees had received any formal pricing or price theory training. UK 1 was typical of the responses: 'no formal training, make it up as you go along'. More commonly interviewees indicated that they had undergone some related training as part of an in-house programme though this was often rather basic:

'I did do a 12 week internal course...... but that was mainly in systems and being mentored' (US 12).

'It's more to do with how to calculate margins and break-even; very basic but some people don't really have any background' (UK 2).

Instead, a number of the interviewees pointed to experiential learning based on doing the pricing job as 'a case of learned practice' (US 5). For example, UK 8 felt that he had effectively served an apprenticeship before rising up the organisation:

'No I've never been taught how to price, well that's not true, during my training and when I was working as an assistant you got to understand how decisions are made and sometimes why' (UK 8).

\section{Decision complexity: rules, buyer-pricing specialist power asymmetries and outcome uncertainty}

\subsection{Rules governing pricing practices and their conflicts}

All interviewees discussed their pricing decision-making process as guided by pricing goals prescribed by the retail organisation that they felt were intended to guide their decision-making behaviour as well as provide objective measures of their performance. As UK 6 , a senior EDLP grocery buyer, put it, 'we use rules, probably better put 'guardrails' for making price decisions'. These goals varied markedly in their complexity. The most common (and simple) pricing goals included competition positioning and minimum margin percentage targets. The former saw interviewees tasked with maintaining a level of price parity with their competitors. Interestingly, such policies tended to be handed down from board level to those responsible for price management - for example, UK 3 suggested the rule 'comes from corporate and then through UK marketing'. These 
goals were either used directly as pricing rules or were interpreted into pricing rules per category and per item type.

'Competitor based rules pricing still dominates with KPIs [Key Performance Indicators] of CPI [Competitor Price Index] and margin percentage' (UK 7).

'The pricing managers work with the buyers to formulate the category strategy that is then converted to a set of business rules' (US 4). ${ }^{4}$

The second simple goal of margin percentage targets emerged within the discussions: Specialist pricing practitioners (price managers and executives) in HiLo retailers used a straightforward margin percentage that was based on only the product cost and regular selling price; in contrast, buyers (in both HiLo and EDLP retailers) and EDLP pricing specialists, used a margin percentage that reflected the actual prices paid by customers, therefore including price promotions, along with the cost and retail price. The rationale for such a distinction appeared to emanate from the ownership and influence of promotions on the final margin. In no situation did a non-'buyer' pricing practitioner have any influence on the promotions run. Due to the rather co-mingled effects of price and promotions, retailers found it hard to isolate the margin revenue affected by regular price decisions alone.

'Margin percent is not perfect but we don't control any other part of the equation' (US 1).

In general, EDLP pricing practitioners did not have to contend with the same levels of promotional activity, so using the achieved margin percentage was still reasonable.

Less frequently, interviewees acknowledged more complex goals and rules, which included additional financial metrics, namely sales revenue and/or margin value (profit). Complex pricing goals were "owned" by pricing executives adopting an EDLP strategy and by buyers across both EDLP and HiLo retailers. They either owned the whole profit and loss (buyers) or were those who could, at least in theory, more easily attribute changes in regular prices to the final margin calculation (EDLP pricing executives). A small number of other metrics were sometimes included such as sales units, waste, and market share. In such instances, there was sometimes a degree of frustration relating to pricing executives' limited agency in the management of these goals:

'We sometimes get market share thrown in there but it's really difficult to measure and ACN data doesn't map properly' (UK 8).

While pricing executives were all set internal goals that they had to abide by, or interpret, in their price decision-making, interviewees discussed difficulties they experienced due to conflicting pricing objectives, particularly the imbalance between competition positioning and financial KPIs. As one frustrated respondent put it: 'how do we remain competitive on the item while still achieving the budgeted gross profit \%?' (US 1). This was less of a concern for buyers, given their complex performance goals, and their stated interpretation of competition parity as a 'guideline' rather than a 'rule', thereby avoiding any major level of dissonance with their commercial objectives. As one pricing manager, UK 1, suggested, buyers were perceived as exhibiting an insular perspective, 'they don't look outside their windows'. On the other hand, the majority of pricing specialists suggested that balancing commercial and competition goals was operationally challenging. The task of balancing pricing goals was more likely to be an issue for HiLo pricing specialists, mainly due to their typical interpretation of pricing goals as 'rules' and their tendency to have the somewhat orthogonal goals of margin percentage and competition positioning.

\subsection{Decision-making challenges in regular pricing practice}

There was a remarkable level of consistency across the pricing decision-makers when they discussed the major issues they felt they had to contend with - these included balancing different goals 
(discussed in previous section), pressures of time, and were also related to the availability of usable data to inform pricing decisions. These challenges were often particularly linked to the organisational context and structure within which they had to work, and therefore the degree of agency and power decision-makers felt they possessed.

\subsubsection{Pricing models and their implications for practitioner agency}

Interviewees suggested that final price change decisions were either owned by the pricing specialist team or by the buyers, although it was not uncommon for multiple stakeholders to also be involved in the final decision-making process. In our sample, based on the interviewees' responses to questions concerning the ownership of pricing decisions, three distinct pricing 'models' or 'roles' emerged from the data that transcended the interviewee's job title, the retailer's pricing strategy and operating country (see Table 4). These are important to briefly explain and framed the entire organisational environment within which pricing practices were acted out.

Table 4 Interviewees by pricing role and the final price decision-maker

\begin{tabular}{|l|l|}
\hline Pricing model (Characteristics) & Ultimate decision-maker \\
\hline $\begin{array}{l}\text { Sellers } \\
\text { Pricing specialists tasked with “selling” their pricing recommendation to } \\
\text { buyer decision-maker. Frustration with buyers' behaviours }\end{array}$ & Buyer \\
\hline $\begin{array}{l}\text { Signallers } \\
\text { Pricing practitioners who tended to indicate the direction of a product } \\
\text { price and to monitor pricing decisions. Oversee buyers' pricing decisions } \\
\text { without the need for a dedicated pricing team. Frustration with buyers' } \\
\text { basic decision-making }\end{array}$ & Buyer \\
\hline $\begin{array}{l}\text { Setters } \\
\text { Buyers and specialist pricing practitioners who were able to approve and } \\
\text { execute their own pricing recommendations to the stores. }\end{array}$ & Buyer / Pricing Specialist \\
\hline
\end{tabular}

'Sellers' were pricing executives who made pricing recommendations but importantly did not control the final price approval. They were particularly seen in US retailers with specialist pricing teams, whose role was to recommend price changes based on pricing goals. Importantly, these recommendations were then subject to final approval by buying teams and, in several situations, the pricing and commercial vice-presidents:

'The buyer has final sign-off; it involves an eight to ten signature process and once around the building type of thing' (US 8).

'The final price is owned by the buyers as they own the whole P\&L [profit and loss accountability]; it would be a massive hurdle to their cooperation if we had control of the prices and therefore their bonus potential. I've positioned us as very much a support group' (US 9).

'Everyone has an opinion on what the price should be and we have ten different opinions' (US 12).

Therefore, sellers had the most extreme goal imbalance in that they had to 'sell' their recommendations to buyers 'to let us take the risk and move the price' (US 5) and to overcome buyers' reluctance given they were 'nervous about moving prices' (US 9). Although price increases were sometimes more palatable, their natural inclination was often regarded as to price as high as possible: 'a dime less than an insult' (UK 1). In addition, sellers perceived that buyers did not take sufficient time to make price approval decisions, and were often perceived as rejecting recommendations out of hand: '[Buyers] accept or reject changes based on very limited amounts of time and often it depends on how bad a mood they are in as to their reaction' (US 7). 
'Signallers' were executives who tended to indicate the direction of a product price, monitor pricing decisions, and often had a small number of high profile product prices to manage themselves. This group consisted of fewer interviewees, though there was a remarkable level of consistency in how they described their role:

'[We act] like a policeman and teacher - making sure we get minimum behaviour and that people are making the most sensible day-to-day decisions' (US 10).

While involved in the day-to-day pricing of high profile products, they were organised to effectively oversee buyers' pricing decisions without the need for a dedicated pricing team: 'We are responsible for the important KVIs [Key Value Items], the systems were changed so that the buyers couldn't change the price' (UK 7). By and large, they had much the same challenges as price sellers in terms of their misalignment with buyers. Indeed, they were often rather vocal in expressing their unsatisfactory relationship with their buyer colleagues in managing price:

'[Buyers] - they are not that bright. There is not a lot of rigour in their decision-making. So their decisions to accept or reject a price change isn't based on much more than their gut instinct' (US 10).

'Setters' were executives who were able to approve and execute their own pricing recommendations to the stores. This group consisted of buyers who owned their category profit \& loss, along with a smaller subset of pricing specialists. These pricing specialists all had 'simple' goals with definite pricing rules, and often justified their role as one that was in place to protect the company's base margins and /or brand image from misuse by the buyers:

'Buyers control the gross profit target and if they can't get a lower cost price they increase the selling price. So to protect our brand image we get to play the police' (US 11).

Pricing specialists in this role saw it as providing a 'separation of powers, checks and balances' (US 11) to their buyers. This group appeared to be the most rules driven, and the most detached from the effects of their decisions on company success, relying upon a strict interpretation of the rules to justify their price change decisions. As one US-based price setter acknowledged:

'I meet with the category teams every week and we go through the price changes. They don't have any say, the rule is the rule' (US 12).

\subsubsection{Insensitivity to market and competitor responses amid time-bound pricing decisions}

As expected in a discussion concerning decision challenges, most interviewees indicated that they were short of time or had lots to do within a restricted amount of time - something which was often linked with a perceived insufficient level of decision-making support:

'It's particularly bad when we do a full book check on a market for one or two key competitors.......not enough time or systems support' (US 3).

Interviewees made reference to having to focus on simply getting price decisions made rather than going through a considered holistic price decision-making process:

'It probably isn't always right but it's a triage with the limited time we have' (UK 7).

The lack of time was exacerbated by a lack of understanding and general uncertainty regarding the likely response of competitors to any price changes - something prevalent irrespective of respondents' country or pricing role. This often led to a tendency for interviewees to discount the benefit of changing price, both in terms of competitor and customer responses: 
'We don't tend to mark-off below Walmart; all they do is reduce their prices too. So we put money on the table and they take it off again. But if you keep level or above them they don't seem to react' (US 12).

'If we break rank, the customer doesn't really give us the credit for it' (UK 7).

Despite the importance of this, there was no evidence that anything more than ad-hoc analysis was being performed to forecast the likely responses of competitors to different pricing changes. This was further compounded by the lack of relevant competition price information: 'We only do these [price checks] six to eight times a year and we don't get a say when they happen - should be more frequent' (US 3). The other major issue that emerged was the poor data quality on competitors when it was collected:

'Getting the correct information on the competitors' prices...[we] need to learn what are keying or user errors' (US 5).

This meant that pricing decision-makers were often disconnected from competition prices and how competitors reacted to their pricing changes.

Pricing executives were faced with inconsistent, poor data that may, or may not, have tied into the competitor's prices or price change cadence. It is then not surprising that not one of the interviewees talked about having a process, or tools, to systematically monitor and forecast competitor price responses:

'Competitive data isn't always there, it's got lots of poor quality so it ends up being a subjective decision and you can't be right all the time' (US 2).

The uncertainty with regards to competitor responses was matched by a lack of data and analytics related to consumer responses to price changes. Many pricing practitioners felt that, because of the lack of information and supportive science, they were forced to rely on their instinct: "Not knowing the price elasticity of the items...... I have to use intuition' (US 3), "We often make a "leap of faith"' (US 7). When the few retailers that did have a commercial IS system capable of forecasting the implications of price changes, our respondents were cautious as to how well the embedded science supported them:

'[I] have one analyst whose only job is to calculate the effects of making the price change....they take a very conservative position on this as it's really hard to do robustly' (US 9).

'We also provide feedback on the price changes, although data are very noisy so [it is] not easy to identify if it's a price, assortment promotion, changing the shelf plan or the price that makes a difference' (US 5).

When combined with the difficulties of managing a wide range of products, and often multiple price zones, pricing practitioners were vulnerable to the emotional or professional recommendations of their stakeholders. For many pricing specialists, this explained their reliance on pricing rules as justification for decisions, while buyers considered such rules as mere guidelines. This left individual product pricing decisions open to significant levels of outcome interpretation.

'They end up justifying the decisions they want to make and reversing into it' (UK 7).

\subsection{Pricing behaviours, tactics and outcomes - inertia and customer-less pricing}

Executives openly acknowledged a pursuit of sub-optimal pricing behaviours. A tendency toward pricing inertia was commonly cited, which, it was argued, was partly driven by uncertainty regarding the likely competitor and customer responses to a price change. Such pressures were exacerbated by 
limited decision-making time and unhelpful support tools, meaning that regular prices remained unchanged unless adjustment was forced - this included returning to original prices following any promotion: 'We do try to leave base prices alone...... don't touch anything unless we really have to' (UK 7). As a result, 'this leads to "sticky prices", probably shouldn't tell you that' (UK 1). Such price 'stickiness' was widely accepted:

'We don't really move the prices unless we have to. It comes back to not having the staff and tools to do much more. We often miss potential price changes' (US 6).

An alternative perspective came from interviewees working for EDLP retailers who believed that moving prices around negatively impacted on customers' 'trust' (UK 3) in the retailer's price commitment:

'We try to move as few prices as possible. We believe that is part of our value equation' (US 9).

'We don't want to move the price unless we have to. It irritates the customer and it also confuses them' (US 11).

An interesting driver of inertia offered by respondents who were buyers and therefore did not have pricing as their core duty (but power over it) was to effectively trivialise the role of regular pricing:

'To be honest I don't do it [make price changes] unless I have to; I'd rather get extra funding from the suppliers for promotions and events as these give me a bigger impact in my year on year sales' (UK 4).

'Pricing is just one of the things I have to think about; sure it's important but I worry more about promotions and availability' (UK 8).

At times, it was recognised by pricing specialists (non-buyers) that price changes were necessary based on product cost or competition price changes. Associated products could also become candidates for price change because they were somehow related to the target product (i.e. different sizes, flavours or brands), but the main stimulus was always cost, margin percentage impact, or a competition-led price change:

'We move so few prices up and those are due to market pressures' (UK 3).

Even with market pressure for reduced prices, the tendency toward inertia was identified where reductions were possible but resisted:

'Unless the market is moving nobody puts the price down and even then if [retailer $\mathrm{x}$ ] doesn't follow, you put the price back up again. It's a very sticky market' (UK 6).

When prices increased, decision-makers argued that they attempted to mitigate risk in their implementation. Price increases were capped to avoid 'sticker shock' (US 2) whilst letting price decreases return to their prescribed level. US 3 talked of capping price increases to $4 \%$ even if it meant undertaking subsequent price uplifts in order to make the appropriate product margin: 'I often end up stretching price increases across months'. In addition to capping price increases, interviewees explicitly referred to limiting the number of price changes sent to the stores for execution to ensure that staff were able to make price changes at the point of sale: 'We tend to cap the number of price changes sent down to the store otherwise we find that they don't get done properly' (US 4).

\section{Developing a model of grocery regular pricing practice}

In this section, we present an inductive model from our data that represents pricing decision-makers' behaviours with respect to regular pricing within our sample of UK and US grocery retailers. As 
noted earlier, the grounded theory approach to analysing our data relied on generating 'theory by developing the hypothetical relationships between conceptual codes (categories and their properties) which have been generated from the data as indicators, to 'discover' a grounded theory' (Glaser, 1978, p.55). The authors open coded and wrote memos after every interview, amassing a total of 142 open codes across 819 interview data strips. Grounded theory encourages researchers to look for a 'core category' while data collection is still in progress. This core category is something that explains the majority of behaviour exhibited by the interviewees and is related to their major cause for concern. Following the determination of the core category, the original open codes were revisited, and recoded, based on their relationship to the core category. 'Selective' codes then emerged, representing a higher level of abstraction than the open codes. To further strengthen the grounded theory process 90 memos were produced. These memos were designed to capture the researcher's thoughts and ideas on individual codes and their interplay - they also formed a convenient library of pre-considered information that helped with the final theory development. The last substantive stage of grounded theory consisted of theoretical coding and the manual sorting of memos in an attempt to identify categories of behaviour and their relationships.

Eight categories were identified having emerged from the memo sorting with a solid level of consistency and a strong relationship to the core category - namely a tendency towards 'price decision coping'. Their relationship appears to follow a 'causes and consequences' model of behaviour (Glaser, 1978, p.74) - see Table 5. 
Table 5: Explanation of model categories and exemplar quotations

\begin{tabular}{|c|c|c|}
\hline & Categories (Explanation) & Exemplar quotations \\
\hline \multirow[t]{2}{*}{ Causes } & $\begin{array}{l}\text { Implicit knowledge of the practitioner } \\
\text { Lack of formal training in the profession and tendency toward on- } \\
\text { the-job instruction }\end{array}$ & 'No formal training, I guess it's a case of learned practice' (US 5). \\
\hline & $\begin{array}{l}\text { Decision complexity } \\
\text { Limited usable information concerning implications of price } \\
\text { changes and internal complexity (e.g. price zones, conflicting } \\
\text { decision rules, promotions) }\end{array}$ & $\begin{array}{l}\text { 'They make it far too complicated, retailer }[\mathrm{X}] \text { had } 64 \text { price zones, and how can you } \\
\text { possibly work with that?' (US 6). }\end{array}$ \\
\hline Condition & $\begin{array}{l}\text { Pricing role } \\
\text { Different roles (Sellers, Setters and Signallers), power and } \\
\text { knowledge asymmetries between 'buyers' and pricing specialists } \\
\text { contributes to passivity pricing }\end{array}$ & $\begin{array}{l}\text { 'The buyer has final sign-off, it involves an eight to ten signature process and once } \\
\text { around the building type of thing' (US 8). }\end{array}$ \\
\hline \multirow{2}{*}{ Consequences } & $\begin{array}{l}\text { Customer-less pricing } \\
\text { Minimal analysis of impact on customers with competitor and } \\
\text { product margin rules dominating decision-making }\end{array}$ & $\begin{array}{l}\text { 'I don't have any customer data' (US 2). } \\
\text { 'The pricing managers work with the buyers to formulate the category strategy that is } \\
\text { then converted to a set of business rules' (US 4). }\end{array}$ \\
\hline & $\begin{array}{l}\text { Enforced symbiosis } \\
\text { Organisational structure to manage price reinforces passivity } \\
\text { pricing }\end{array}$ & $\begin{array}{l}\text { 'Buyers hate making price changes and hate the pricing policy because they see it as } \\
\text { giving their success and bonus away often for no uptick in sales' (UK 5). }\end{array}$ \\
\hline
\end{tabular}


The model that emerges is particularly useful for explaining pricing behaviour of UK and US grocers, and led to the formalizing of this model as the theory of 'Passivity' Pricing (see Figure 1).

Figure $1 \quad$ Passivity pricing overlaid on Glaser's 6C theoretical model

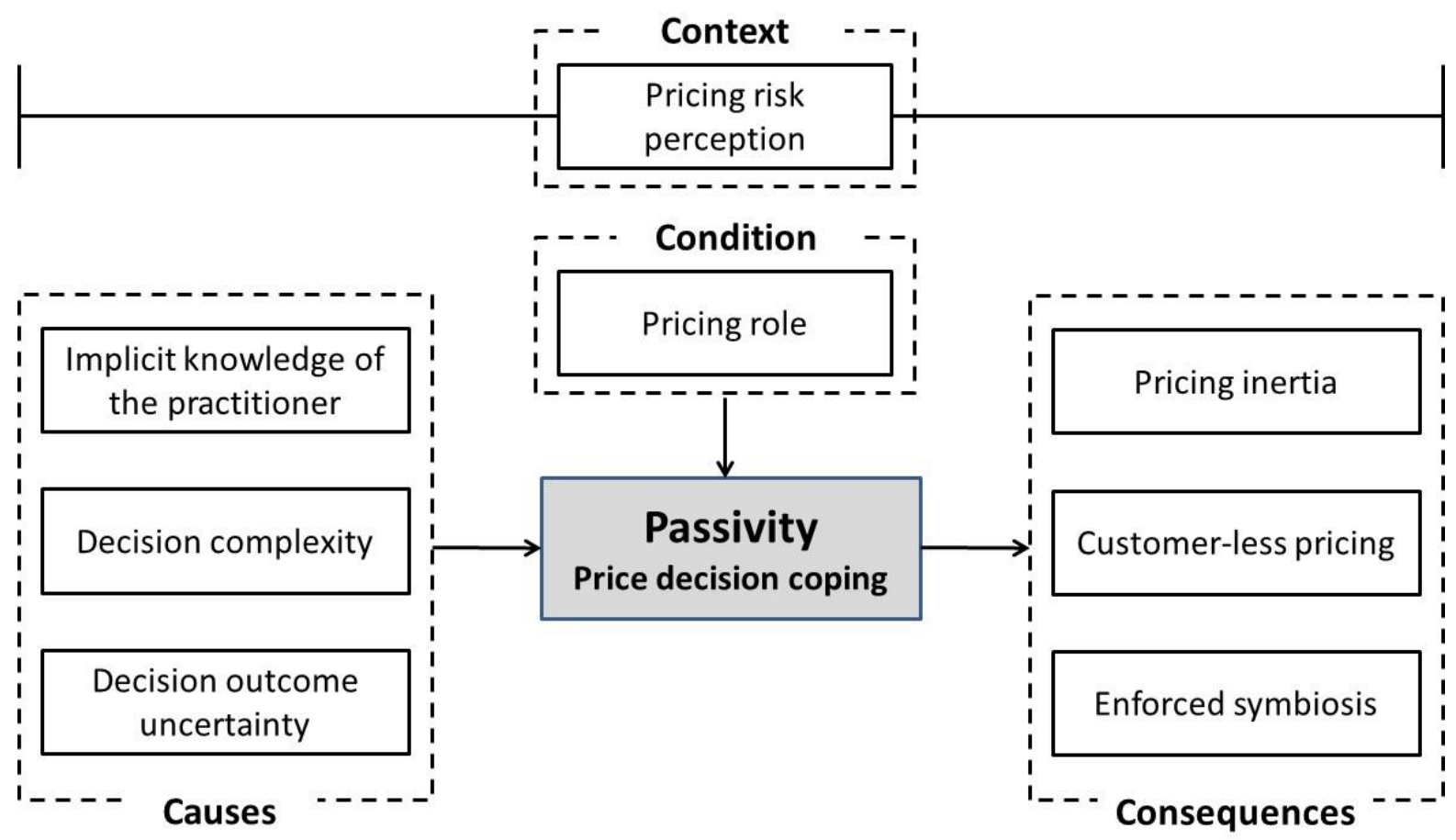

The pricing context is one where pricing decisions were seen as important but also inherently risky. While small price increases make a significantly positive impact on profits, particularly if sales volumes remain unaffected, they were also seen as likely to create a level of dissonance among customers who were sensitive to that product's price. Leaving prices alone - being consistent - was believed to improve the likelihood that customers form a 'trusting relationship' with their grocer.

A condition affecting the tendency toward passivity, and a focus on coping rather than leading in a price role, was related to the different pricing roles of the different actors we identified. Whether sellers, signallers or setters, all pricing roles exhibited a degree of passivity, with only setters and, to some extent, signallers being seen to partly resist.

Causes include 'decision complexity' given that regular price decision-makers possessed very little information concerning their customers beyond aggregate sales and market share data. Such difficulties were heightened due to the internal complexity many practitioners faced due to multiple price zones (in the US), decision rules, the impact of promotions and the power relations with stakeholders. The unpredictable nature of customer reactions and the lack of scientific support led to considerable 'decision outcome uncertainty' - something linked more broadly to the 'implicit knowledge of the practitioners' given that they were not formally trained with a lack of behaviours and standards formalised within the role.

These contexts, conditions and causes led to a range of consequences which included 'pricing inertia' - a reluctance to move product prices and actively engage in pricing - in other words, thoughtful and informed price decision-making. Instead, prices were only changed based on mandatory rules and minimum requirements rather than to optimise performance. Given this risk adverse backdrop of 
competitor and margin rules dominating pricing, the process became 'customer-less' which perpetuated passivity pricing behaviours.

One consequence of the retailers' attitude to regular price decision-making is the organisational structure that emerged to manage price decisions. Our research suggests that when buyers and pricing specialists manage pricing decisions, the behaviour of the buyer reinforces pricing passivity through an ego state called 'symbiosis' - a term borrowed from biology. As Schiff and Schiff (1971, p 71) note, 'symbiosis occurs when two or more individuals behave as though between them they form a whole personality'. Instead of two people each playing any of the three roles (parent, adult or child), the ego states are rolled into one with the different parties occupying different states. In grocery pricing, it is seen that the buyer holds the role of both parent and child. The parent is the role of the approval giver that exercises a dominating influence, whereas the child is driven by emotion and what $\mathrm{s} / \mathrm{he}$ feels is the right thing to do. The buyer is able to utilise either of these states when dealing with pricing decisions. The pricing specialist is left playing the remaining adult role; making what they believe are rational and logical recommendations. Both parties maintain the symbiotic state through behaviour called 'discounting' ( $c f$. Schiff and Schiff, 1971). From the buyers' perspective, the significance of the problem is discounted: 'If we drop the price of non KVI items we don't see a flicker in change of volume' (UK 5). In turn, the ability to solve the problem is discounted:

'I think customer buying is so complicated - all we should do is to incrementally improve the food that we offer and make the price as compelling as possible but do it through promotions and discounts as they really drive the volume' (UK 2).

Pricing specialists themselves exhibit discounting traits that perversely reinforces their own behaviour by discounting the person, in this case the buyer: 'They [buyers] also lack the tools and, being quite blunt, they often lack the skill set; they are not that bright' (US 10).

Pricing organisations trap sellers and signallers with this 'enforced symbiotic' behaviour model while setters themselves exhibit similar behaviour referring to imposed company pricing rules to justify their own pricing decision-making. Particularly for the former two groups, sellers and signallers, this is frustrating and a source of sub-optimal behaviour and decisions.

\section{Discussion and Conclusions}

The price of a product found in a grocery store is profoundly important to both the customer and to the retailer. Despite this, the academic pricing literature tends to focus on pricing strategy (e.g. EDLP, HiLo) at the expense of interrogating pricing practices within the retail firm (Fassnacht and El Husseini, 2013; Ingenbleek and van der Lans, 2013). Our paper makes the argument for research that is applied, and therefore contextually and operationally relevant: understanding the current pricing context by accessing the situated knowledge of pricing executives is a step forward to achieving this.

Drawing on data from our extensive sample of US and UK grocery pricing executives, working for retailers accounting $64 \%$ and $85 \%$ of grocery retail sales in the two respective markets, leads to the development of the theory of Passivity Pricing. The model that emerges from the data is based on Glaser's 6C paradigm (Glaser, 1978). This grounded theory of pricing practice therefore offers grocery and pricing management a clear model that explains current pricing practices in our sample a view of 'what is actually going on, not what ought to go on' (Glaser, 1978, p.14).

Our findings further develop our academic understanding of pricing tactics by offering a more complete integrated model than previously seen. While Hall et al. (1997) took a univariate approach to discussing the explanations behind price rigidity, they made no attempt to integrate the cause and effects. In a more integrated example, McGoldrick (2002) provided a theoretical multi-dimensional model that represented the inputs to retail pricing decisions. However, it lacked a pricing practitioner perspective regarding how these factors combine with internal processes (e.g. price change approvals), or how the model varies based on different pricing strategies or roles. The only other 
class of models seen in the literature are best described as organising models (e.g. Grewal et al., 2011) and are typically used in meta-analysis articles. It is clear that all of these non-grounded models, while offering an outside view, lack the insight offered by looking conceptually and holistically at the behaviour of pricing decision-makers themselves. As such, none of the existing models offer the reader explanatory support for understanding current price decision-making practices.

Compared to research on broader pricing strategy, the practice-based reality of managing regular price has been exposed as something different - reflecting a division between perceived strategy and actual practice that remains a wider concern of management studies (Jarzabkowski and Spee, 2009). While sophistication in pricing management through price optimization software may be identified in some retail sectors (e.g. Bolton et al., 2010), it appears to be distanced from many regular grocery pricing decisions. The revealed tendency toward passivity by pricing executives resorts to what Das and Teng (1999) refer to as an 'avoidance mode' of decision making whereby organisational decision-makers resist change, avoid uncertainty and therefore maintain the status quo ( $c f$. Cyert and March, 1963). In essence then, there are too many unknown implications of changing prices in terms of competitor and consumer responses which reinforces a situation of relying on past practice. This state, rich with causal ambiguity, means that there is a perceived high cost of experimenting with price changes and therefore the length of time in a price executive role does not necessarily lead to wisdom ( $c f$. Denrell, 2008). Ultimately decision-making paralysis pervades as there is a lack of knowledge of effects of any price changes such that one is reminded of the infamous statement by former United States Secretary of Defense, Donald Rumsfeld concerning making high risk decisions with imperfect data:

'...there are known knowns; there are things we know we know. We also know there are known unknowns; that is to say we know there are some things [we know] we do not know. But there are also unknown unknowns - the ones we don't know we don't know' (Rumsfeld, 2011, p.xiii)

In addition to the paralysis stemming from the lack of knowledge of consumer and competitive implications of changing prices, there was also an organisational element that further reinforced the status quo. Routines and rule-based norms of behaviour of passivity have become embedded within retail organisations between sellers, signallers and setters. As acknowledged earlier, such routine rigidity can become a source of inertia (Gilbert, 2005) and characteristic of 'locked in' practice (Volberda, 2006). The division of responsibilities between buyers and pricing executives frequently led to conflict given incompatible targets, rules and responsibilities. Such situations are recognised more widely within management research as 'different communities may be bound by existing power relationships and subjective constructions of the work process that inhibit adoption of a practice' (Jarzabkowski, 2004, p.548-9). These ossified organisational practices require upheaval; placing an emphasis on management restructuring of work routines, responsibilities and procedures which are potentially disruptive, threaten certain interest groups, and likely lead to resistance.

\subsection{Practical implications}

We argue that our findings have the potential to improve management through enhanced awareness of contemporary practical price management. Three key areas appear to particularly require management attention:

First, the allocation of roles and responsibilities within the management of regular pricing often leads to internal conflict and sub-optimal outcomes. This is especially seen in the uneven and inconsistent balance of power and duties between buyers and pricing specialists. Clearer lines of authority, accountability and incentivisation need to be established - but equally, pricing rules need to be sufficiently flexible for price optimisation in reality. Achieving such a reorganised streamlining and clarification of responsibilities will be challenging to achieve - not least as buyers have traditionally held the 'whip hand' within retail organisations ( $c f$. Davies, 1994). 
Second, while pricing optimization software is often discussed within the academic retail marketing literature (Bolton et al., 2010), there appears to be a lack of practical and timely application of the systems employed, with little understanding of likely customer and competitor responses. Decision support systems must be in a form that can be practically employed by pricing executives. There is a role in this respect for the academic discipline of marketing by contributing to the development of practically useful and organisationally embedded price modelling tools. Our data suggests that the academic discipline of marketing science appears to have fallen short of affecting positive change in practical pricing practice ( $c f$. Roberts et al., 2014). Addressing this lacuna will require retail marketing academics to work with retailers and price practitioners to understand their day-to-day needs.

Finally, with greater development of the technical support for pricing specialists, it is essential that the role of pricing executives is given greater currency within retail organisations and that executives receive sufficient training in the emerging discipline. Instead, the profession is often framed by respondents as one they 'drifted into' with minimum support or guidance.

\subsection{Limitations and directions for future research}

There are several limitations inherent in the current study associated with the research context and research design. Our study was focused on the management of regular prices and therefore excluded consideration of promotions which clearly underpin important aspects of retail competition. While our sample is extensive, it cannot claim to be necessarily generalizable across the UK and US grocery retail markets or beyond. Although it included the main pricing decision-makers within our sample of grocery retailers, it arguably overlooked alternative insights from other actors that affect the regular pricing process within each firm. In addition, our respondents tended to work within larger food retail firms so we likely under-represented smaller and mid-sized retail organisations. In terms of our approach to data collection, our methodology section acknowledged the limitations related to undertaking telephone rather than face-to-face interviews. Finally, of course, what any new pricing structure and decision-making processes should look like are beyond the immediate scope of this research and present further opportunities for industry engaged retail marketing scholarship.

In the future, it would be interesting to assess whether the passivity pricing state found in this study is a characteristic of other retail sub-verticals, such as general merchandise and clothing retailers that are typically less burdened by such an overwhelming number of SKUs or rapidity of stock turn (given the lack of sell-by dates and sensitivity to temperature). Given the qualitative, inductive approach adopted, there are further opportunities to quantitatively test the model of passivity pricing within a grocery context - specifically to measure the strength of the relationships between the various 'causes' and 'consequences' identified in Figure 1. From another perspective, in-depth case study research of retailers would generate a richness of data concerning the intra-firm interaction between different actors in the pricing process and further interrogate the findings we have identified. Given our recognition of the causes of passivity pricing, there is the possibility that 'action research', operationalized in conjunction with grocery retailers, could assess attempts to address the sub-optimal pricing practices highlighted by our research.

\section{ENDNOTES}

${ }^{1}$ We use the terms 'pricing practitioner', 'pricing executive' or 'price decision-maker' interchangeably to relate to the respondents responsible for pricing who made up our respondents.

${ }^{2}$ This distinction between pricing strategies and practices is borrowed from Ingenbleek and van der Lans (2013). 
${ }^{3}$ The qualitative data analysis followed the following procedure detailed below:

Open Coding - Open coding is the initial level of coding where data incidents are coded based on what the researcher is seeing in the data. This is different to research methods that pre-determine the outcome codes and then fit them to the research data (Kelle, 2007). Open coding forced the researcher to 'verify and saturate categories' (Horton, 2008, p 82). Three rounds of open coding were completed, each with a progressive level of focus coming from the emerging 'core category'.

Constant Comparative technique - Theoretical saturation was achieved through constant comparison of incidents (indicators) in the data to elicit the properties and dimensions of each category (code) (Holton, 2008, p.265). Open codes were used in the first level of constant comparative analysis where 'incidents are compared to incidents to establish underlying uniformity and varying conditions' (Holton, 2008, p.82). Some of these turned into substantive codes that were conceptualized into concepts and properties of concepts (Glaser, 1998, p.135). Concepts were then compared to new data and codes, helping to elaborate the conceptual categories, prior to reaching 'saturation'. Finally concepts were compared to concepts and the emergence of theoretical codes wove them together into the emerging theory. Constant comparison was particularly useful to this study, helping to move away from merely describing what was said by the pricing executives towards an understanding of their decision making behaviour and its drivers.

Selective Coding and Delimiting - Once the study's core category, namely 'price decision coping', had been identified open coding stopped and only codes whose variables significantly related to the core were focused on. Further data collection and coding were effectively 'delimited' to those target codes. The practical implications of this were limited as the core category successfully linked all the categories together leaving few codes that could be deselected in the process, 'underlying uniformity' (Glaser and Holton, 2004, p.15). The number of codes went down considerably from open coding to selective coding.

Memoing - Memos are theoretical notes about the data and the conceptual connections between categories (Holton, 2008, p.85) and are core to successful theory building. While they involve writing detailed descriptions, these descriptions are 'subsumed' in the analysis as they are raised to an abstract, or conceptual, level. The memoing shadowed the constant comparative process as it is believed that the construction of memos slows the researchers down, introducing a 'pacing' effect, while allowing them to breakdown internal preconditions or to help raise any issues or gaps in the data. Approximately 85 memos were raised during the course of the open and selective coding, with additional memos being raised during the 'sorting and writing up' phase where conceptual relations were further developed into a substantive theory.

Theoretical coding and sorting - Having finished coding and memoing, the researcher then brought the 'fractured data back together' (Glaser and Holton, 2004, pp.18) by reviewing, sorting and integrating the memo bank to the core category. Sorting and pairing memos based on their fit, 'similarities, connections and conceptual orderings' (Glaser and Holton, 2004, pp.18), to other connected memos allowed the multivariate model outline to emerge that explained the relationships between the codes. Time was then spent examining theoretical models (Glaser, 2005) endeavouring to understand if there was a natural fit based on the emerged concepts and their relationships to each other. The $6 \mathrm{C}$ 's theoretical model of cause and consequence (Glaser, 1978, p 74) was an applicable hypothesis as it encompassed all of the codes and categories and was basis for the substantive theory as discussed toward the end of the paper.

${ }^{4}$ Interestingly, while many assume that category managers own - or at least drive - many grocery pricing decisions, our sample of grocery retailers suggest otherwise. Instead, in simplified terms, category managers tend to act more as planners who support the buyers. They certainly have profit KPIs, but they tend not to own the final sign-off; that is for the buyer.

\section{References}

Alvesson, M. (2003), "Beyond neopositivists, romantics, and localists: a reflexive approach to interviews in organizational research", Academy of Management Review, Vol. 28 No. 1, pp. 13-33.

Alvesson, M. (2011), Interpreting Interviews. SAGE Publications Ltd, SAGE Publications Ltd, London. 
Alvesson, M. and Sköldberg, K. (2009), Reflexive methodology: New Vistas for Qualitative Research, Sage, London, UK.

Angell, R., Megicks, P., Memery, J., Heffernan, T. and Howell, K. (2012), "Understanding the older shopper: A behavioural typology”, Journal of Retailing and Consumer Services, Vol. 19 No. 2, pp. 259-269.

Armstrong, D., Gosling, A, Weinman, J. and Marteau, T. (1997). "The place of inter-rater reliability in qualitative research: an empirical study", Sociology, Vol. 31 No. 3, pp. 597-606.

Bell, D. and Lattin, J., (1998), "Shopping behaviour and consumer preference for store format: why "large basket" shoppers prefer EDLP”, Marketing Science, Vol. 17 No. 1, pp. 66-88.

Bergen, M., Dutta, S., Ritson, M. and Zbaracki, M. (2002), "Pricing as a strategic capability", Sloan Management Review, Vol. 43 No. 3, pp. 61-66.

Binkley, J. K. and Connor, J. M. (1998) "Grocery market pricing and the new competitive environment", Journal of Retailing, Vol 74 No 2, pp. 273-94.

Blattberg, R. and Neslin, S., (1990), Sales Promotion; Concepts, Methods and Strategies, Englewood Cliffs, NJ: Prentice Hall.

Bolton, R.N. and Shankar, V. (2003), “An empirically derived taxonomy of retailer pricing and promotion strategies”, Journal of Retailing, Vol. 79 No. 4, pp. 213-224.

Bolton, R., Shankar, V. and Montoya, D., (2010), "Pricing: recent trends and emerging practices in retailer pricing” In M. Kraft \& M. Mantrala, eds. Retailing in the 21st Century. Heidelberg: SpringerLink, pp. $245-269$.

Bryman, A. and Bell, E. (2011), Business Research Methods, Oxford University Press, Oxford, UK.

Burt, S., Sparks, L. and Teller, C. (2010), "Retailing in the United Kingdom - a Synopsis". In European Retail Research, eds. P. Schnedlitz, D. Morschett, T. Rudolph, H. Schramm-Klein \& B. Swoboda, pp. 173-194. Gabler.

Business Week. (2000), The power of smart pricing. (April 10). http://www.businessweek.com/2000/00_15/bl3676/33.htm.

Charmaz, K., (2013), Constructing Grounded Theory: A Practical Guide through Qualitative Analysis, Thousand Oaks, CA: Sage.

Chintagunta, P., (2002), "Investigating category pricing behavior at a retail chain", Journal of Marketing Research, Vol. 39 No. 2, pp. 141-154.

Chung, J. and Li, D. (2014), "A simulation of the impacts of dynamic price management for perishable foods on retailer performance in the presence of need-driven purchasing consumers", Journal of the Operational Research Society, Vol. 65 No. 8, pp. 1177-1188.

Cyert, R. M. and March, J. G. (1963), A Behavioral Theory of the Firm, Prentice-Hall, Englewood Cliffs, N.J.

Das, T. and Teng, B. S. (1999), "Cognitive biases and strategic decision processes: An integrative perspective”, Journal of Management Studies, Vol. 36 No. 6, pp. 757-778.

Davies, G. (1994), “The delisting of products by retail buyers”, Journal of Marketing Management, Vol. 10 No. 6, pp. 473-493. 
Denrell, J. (2008), "Superstitious behavior as a byproduct of intelligent adaptation", in Hodgkinson, G. and Starbuck, W. (Eds.), The Oxford Handbook of Organizational Decision Making. Oxford University Press, Oxford, UK, pp. 271-286.

Diamantopoulos, A., (2003), “Pricing”. In M. Baker, ed. The Marketing Book. Oxford: Elsevier, pp. $342-359$.

Dolan, R. and Simon, H, (1996), Power Pricing: How Managing Price Transforms the Bottom Line, New York: The Free Press.

Ellickson, P., Misra, S. and Nair, H. S. (2012), "Repositioning dynamics and pricing strategy", Journal of Marketing Research, Vol. 49 No. 6, pp. 750-772.

Ellickson, P. and Misra, S, (2008), “Supermarket pricing strategies”, Marketing Science, Vol. 27 No. 5, pp. $811-828$.

Fassnacht, M. and El Husseini, S. (2013), "EDLP versus Hi-Lo pricing strategies in retailing-a state of the art article”, Journal of Business Economics, Vol. 83 No. 3, pp. 259-289.

Gauri, D.K. (2013), "Benchmarking retail productivity considering retail pricing and format strategy", Journal of Retailing, Vol. 89 No. 1, pp. 1-14.

Gauri, D., Trivedi, M. and Grewal, D., (2008), "Understanding the determinants of retail strategy: an empirical analysis", Journal of Retailing, Vol. 84 No. 3, pp. 256-267.

Gilbert, C. (2005), "Unbundling the structure of inertia: resource versus routine rigidity", Academy of Management Journal, Vol. 48 No. 5, pp. 741.

Gioia, D. A., Corley, K. G. and Hamilton, A. L. (2013), "Seeking qualitative rigor in inductive research: notes on the Gioia methodology", Organizational Research Methods, Vol. 16 No. 1, pp. 15-31.

Glaser, B., (1978), Theoretical Sensitivity: Advances in the Methodology of Grounded Theory, Mill Valley, CA: Sociology Press.

Glaser, B., (1998), Doing Grounded Theory: Issues and Discussions, Mill Valley, CA: Sociology Press.

Glaser, B. G. (2005), The Grounded Theory Perspective III: Theoretical Coding. Mill Valley, CA: Sociology Press.

Glaser, B.G. and Holton, J. (2004), "Remodeling grounded theory", Historical Social Research/Historische Sozialforschung. Supplement Vol. 5 No.2, pp. 47-68.

Grewal, D., Ailawadi, K.L., Gauri, D., Hall, K., Kopalle, P. and Robertson, J.R. (2011), "Innovations in retail pricing and promotions", Journal of Retailing, Vol. 87 No. S1, pp. S43-S52.

Haans, H. \& Gijsbrechts, E. (2011) ““‘One-deal-fits-all?” On category sales promotion effectiveness in smaller versus larger supermarkets”, Journal of Retailing, Vol 87 No 4, pp. 427-43.

Hall, S., Walsh, M. and Yates, A. (1997), How Do U.K. Companies Set Prices? Bank of England Working Paper No. 67, July 1997, Bank of England, Threadneedle Street, London, EC2R 8AH.

Hemscott Americas, (2012), Industry Summary. Yahoo Finance. Available at: http://biz.yahoo.com/p/sum_qpmd.html.

Hoch, S., Dreze, X. and Purk, M., (1994), “EDLP, Hi-Lo, and margin arithmetic”, Journal of Marketing, Vol. 48 No. 4 , pp. $16-27$. 
Hodgkinson, G. and Starbuck, W. (2008), “Organizational decision making: mapping terrains on different planets", in Hodgkinson, G. and Starbuck, W. (Eds.), The Oxford Handbook of Organizational Decision Making. Oxford University Press, Oxford, UK, pp. 1-29.

Holton, J. A. (2008), “Grounded theory as a general research methodology”, The Grounded Theory Review, Vol. 7No. 2, pp. 67-93.

Ingenbleek, P. T. M. and van der Lans, I. A. (2013), "Relating price strategies and price-setting practices", European Journal of Marketing, Vol. 47 No. 1/2, pp. 27-48.

Jarzabkowski, P. (2004), “Strategy as practice: recursiveness, adaptation, and practices-in-use”, Organization Studies, Vol. 25 No. 4, pp. 529-560.

Jarzabkowski, P. and Spee, A. P. (2009), "Strategy-as-practice: A review and future directions for the field", International Journal of Management Reviews, Vol. 11 No. 1, pp. 69-95.

Jensen, B. B. and Grunert, K. G. (2014), "Price knowledge during grocery shopping: what we learn and what we forget”, Journal of Retailing, Vol. 90 No. 3, pp. 332-346.

Kahneman, D. and Tversky, A., (1979), "Prospect theory: an analysis of decision under risk", Econometrica, Vol. 47 No. 2, pp. 263-292.

Kantar Worldpanel. (2013), Grocery Share Figures for the 12 Weeks Ending 7 July 2013. Accessed at http://uk.kantar.com/media/445345/16_07_13_kantar_worldpanel_supermarket_share_data_and_comment ary.pdf

Kelle, U. (2007). The development of categories: Different approaches in grounded theory, in: Bryant, A., Charmaz, K. (Eds.), The Sage Handbook of Grounded Theory. Sage, London, pp. 191-213.

Kopalle, P., Biswas, D., Chintagunta, P. K., Fan, J., Pauwels, K., Ratchford, B. T. and Sills, J.A. (2009), "Retailer pricing and competitive effects", Journal of Retailing, Vol. 85 No. 1, pp. 56-70.

Kvale, S. and Brinkmann, S., (2008), Interviews: An Introduction to Qualitative Research Interviewing 2nd ed., Thousand Oaks, CA: Sage.

Lal, R. and Rao, V., (1997), "Supermarket competition: the case of every day low pricing”, Marketing Science, Vol. 16 No. 1, pp. 60-80.

Lee, N. and Greenley, G. (2010), "The theory-practice divide: thoughts from the Editors and Senior Advisory Board of EJM”, European Journal of Marketing, Vol. 44 No. 1/2, pp. 5-20.

Levy, M., Grewal, D., Kopalle, P. K. and Hess, J. D. (2004), "Emerging trends in retail pricing practice: implications for research", Journal of Retailing, Vol. 80 No. 3, pp. xiii-xxi.

McGoldrick, P., (2002), “A multi-dimensional framework for retail pricing”. In A. Findlay \& L. Sparks, eds. Retailing: Critical Concepts. London: Routledge, pp. 247-269.

March, J. G. (1997), “Understanding how decisions happen in organizations”, in Shapira, Z. (Ed.), Organizational Decision Making. Cambridge University Press, Cambridge, UK, pp. 9-32.

Maule, A. and Hodgkinson, G. (2002), "Heuristics, biases and strategic decision making”, The Psychologist, Vol. 15 No. 2, pp. 68-71.

Megicks, P., Memery, J. and Williams, J. (2008). "Influences on ethical and socially responsible shopping: evidence from the UK grocery sector", Journal of Marketing Management, Vol. 24 No. 5-6, pp. 637-659. 
Miller, S., Wilson, D. (2006), "Perspectives on Organizational Decision-making”, in Clegg, S. Hardy, C., Lawrence, T. B., Nord, W. (Eds.), Handbook of Organization Studies, Sage Publications, London, pp. 467484.

Monroe, K.B. (2003), Pricing: Making Profitable Decisions, 3rd ed., McGraw-Hill Irwin, Burr Ridge, IL

New York Times (2012), “Shopper alert: price may drop for you alone”, New York Times, August 9, 2012.

Nijs, V., Srinivasan, S. and Pauwels, K., (2007), "Retail-price drivers and retailer profits”, Marketing Science, Vol. 26 No.4, pp. 473-487.

Oxenfeldt, A.R. (1973), “A decision-making structure for price decisions”, Journal of Marketing, Vol. 37 No. 1, pp. 48-53.

Phillips, R., (2005), Pricing and Revenue Optimization, Stanford, CA: Stanford University Press.

Pidgeon, N. and Henwood, K. (2009) "Grounded theory”. In Hardy, M. and Bryman, A. (eds.) (2009) Handbook of Data Analysis, London: SAGE, pp. 625-648.

Reibstein, D.J., G. Day and J. Wind. (2009), “Guest editorial: is marketing academia losing its way?” Journal of Marketing, Vol. 73 No. 4, pp. 1-3.

Reus, T. H., Ranft, A. L., Lamont, B. T. and Adams, G. L. (2009), “An interpretive systems view of knowledge investments”, Academy of Management Review, Vol. 34 No. 3, pp. 382.

Roberts, J. H., Kayande, U. and Stremersch, S. (2014), "From academic research to marketing practice: Exploring the marketing science value chain", International Journal of Research in Marketing, Vol. 31 No. 2, pp. 127-140.

Rotemberg, J. and Saloner, G., (1990), "Collusive price leadership", The Journal of Industrial Economics, Vol. 39 No. 1, pp. 93-111.

Rumsfeld, D. (2011) Known and Unknown: A Memoir, London: Penguin.

Schiff, A. and Schiff, J., (1971), Passivity. Transactional Analysis Journal, Vol. 1 No. 1, pp. 71-80.

Shankar, V. and Bolton, R., (2004), “An empirical analysis of determinants of retailer pricing strategy", Marketing Science, Vol. 23 No. 1, pp. 28-49.

Simon, H. (1959), "Theories of decision-making in economics and behavioural science", The American Economic Review, Vol. 49 No. 3, pp. 253-283.

Simon, H.,von der Gathen, A. and Daus, P. (2010) 'Retail pricing - higher profits through improved pricing processes'. In M. Kraft \& M. Mantrala, eds. Retailing in the 21st Century. Heidelberg: SpringerLink, pp. 271-288.

Srinivasan, S., Pauwels, K. and Nijs, V., (2003), Retail Price Drivers and their Financial Consequences, Tuck School of Business, Dartmouth College, NH.

Srinivasan, S., Pauwels, K. and Nijs, V., (2008), "Demand-based pricing versus past-price dependence: a costbenefit analysis”, Journal of Marketing, Vol. 72 No. 2, pp. 15-27.

USDA, (2012), ERS Food Expenditure Series. Economic Research Service. Available at: http://www.ers.usda.gov/data-products/food-expenditures.aspx 
Volberda, H. W. (2006), "Strategic flexibility creating dynamic capability”, in Faulkner, D. O. and Campbell, A. (Eds.), The Oxford Handbook of Strategy. Oxford University Press, Oxford, UK, pp. 939-998.

Volpe, R. (2011), "Evaluating the performance of us supermarkets: pricing strategies, competition from hypermarkets, and private labels", Journal of Agricultural and Resource Economics, Vol. 36 No. 3, pp. 488-503.

Wang, X. and Li, D. (2012), "A dynamic product quality evaluation based pricing model for perishable food supply chains", Omega, Vol. 40 No. 6, pp. 906-917.

Wengraf, T., (2004), Qualitative Research Interviewing: Biographic Narrative and Semi-Structured Methods, Thousand Oaks, CA: Sage.

Zielke, S. (2010), "How price image dimensions influence shopping intentions for different store formats", European Journal of Marketing, Vol. 44 No. 6, pp. 748-770.

Zielke, S. (2011), "Integrating emotions in the analysis of retail price images", Psychology and Marketing, Vol. 28 No. 4, pp. 330-359. 